\title{
Ions from Liquid Gold
}

\section{FIELD EMISSION SYSTEMS FOR APPLICATIONS IN HIGH TECHNOLOGY}

\author{
Philip D. Prewett \\ Dubilier Scientific Itd., Abingdon, Oxfordshire, U.K.
}

\begin{abstract}
The application of a bigh electric field to the surface of a liquid metal in vacuum can produce intense beams of metal ions or a beam containing both ions and charged droplets. The field emission systems based upon these processes, in the development of which liquid gold is used extensively, show considerable promise for bigh technology applications. In particular, the manufacture of submicron very large scale integrated (VLSI) microcircuits, and bybrid microcircuits may be radically affected.
\end{abstract}

One of the distinguishing features of modern high technology is an increased awareness of the importance of the surface as well as the bulk properties of materials. This has led to the development of a large number of techniques for processing surfaces to modify both their chemical and physical properties. The electrochemical passivation of surfaces is, for example, commonly used, as is the production of surface coatings of the nobler metals, including gold, by electroplating. Gold plating is, of course, widely used in electrotechnology wherever high conductivity electrical contacts and interconnecting pathways are required.

While the development of surface treatments in general has been a noticeable trend in tecent years, the use of ion beam and ion beam assisted techniques to effect surface processing has undergone a dramatic growth during the last decade. In the coatings field, for example, the various ion plating techniques (1) are now recognized to have several important advantages over 'wet' techniques such as electroplating and these include:

(1) No harmful effluent

(2) Vacuum cleanliness

(3) Improved film quality

(4) Good adhesion

(5) Excellent throwing power.

The last is a particular feature of ion plating and can be very useful when coating complex shapes including re-entrant features. In the semiconductor field, ion beam machining or milling is playing an important role in the development of microcircuit production techniques. However, arguably, the single most important existing ion beam production technique in the semiconductor industry is ion implantation (2) which is used to dope semiconductor silicon in order to modify its electronic properties. Until now this process has always relied upon the use of ion-absorbing masks together with beams of relatively large area to delineate the doped regions. Recently, however, some excitement surrounds the possibility of maskless processing of semiconductors using finely focussed ion beams to produce the extremely small doped regions which will be required as the pattern definition of advanced microcircuits approaches the submicron scale.
Both the liquid metal field emission systems described in this article have potential applications in the semiconductor industry and it is in this area that their impact is likely to be most significant. As we shall see, gold is playing a role in the latest development of both systems.

The fundamental structure of the two field emission systems will be described in the next section, followed by a discussion of their applications, with the emphasis on the semiconductor industry.

\section{Liquid Metal Field Emission Systems}

There are two liquid metal field emission systems under current development - the liquid metal ion source (LMIS) and the field emission deposition (FED) sprayer. The former (3) produces a beam of metal ions only, while the latter produces a mixed beam or 'spray' of metal ions and charged liquid droplets. The FED sprayer is used to produce coatings of gold by direct impact of its spray upon a cool substrate while the LMIS has a wide range of other ion beam processing and analysis functions including direct implantation. The basic elements are common to both systems and are shown in Figure 1.

A needle, produced from a wire by electrochemical etching, protrudes from a reservoir containing the liquid metal. The needle is wetted with the liquid during the manufacturing process to produce a film extending over its surface from reservoir to apex. An electric field stress is applied to this liquid metal film by applying a potential difference of several kilovolts between the emitter and a nearby counter-electrode or extractor. Much of the early experimental work on LMIS's was performed using liquid gallium $(4,5)$ as the source of ions because of its low melting point $\left(29.3^{\circ} \mathrm{C}\right)$. More recently, the need for sources using high melting point metals has led to the development of resistively heated high temperature furnaces to enclose the reservoir and needle. Present furnaces can be used to produce sources of gold (6), which melts at $1060^{\circ} \mathrm{C}$, and other materials having high melting points.

In the case of an LMIS the tip of the source needle has a radius of $\sim 10 \mu \mathrm{m}$. The application of a voltage, normally in the range $4-10 \mathrm{kV}$, between the needle and extractor is sufficient to cause 
distortion of the liquid film on the apex of the needle. The precise size and shape of the liquid protrusion produced in this way is still the subject of some scientific debate, but it closely resembles a Taylor Cone (7) which can be formed when surface tension and electrical stresses balance on the surface of a liquid. Whatever the precise shape of the distorted film, the electric field at its surface is sufficiently high to cause ions to be ripped out of the liquid to form a small bright ion emitting region at the tip of the protrusion. The exact mechanism of this emission is again uncertain but is most likely (8) to be the process known as field evaporation or field desorption $(9,10)$.

The source is designed so that flow of liquid to the emitting region is limited by the hydrodynamic impedance of the system.

In the case of the FED sprayer, on the other hand, a source having much lower flow impedance is utilized. The configuration is essentially the same as that of the LMIS (see Figure 1) but a needle having a blunter tip (radius $>60 \mu \mathrm{m}$ ) is normally employed. The FED system therefore requires a higher voltage for creation of the Taylor Cone $(\sim 11 \mathrm{kV})$, but once switched on it delivers an ion current just like the LMIS. However, if the applied field is now raised well beyond the threshold field, by raising the applied voltage to $>13 \mathrm{kV}$, the FED system begins to emit a stream of liquid droplets in addition to ions. The electric field stress at the apex of the needle is now so high that the liquid film is not just disorted but suffers gross disruption leading to the emission of globules or droplets of liquid metal. These droplets vary in size according to the conditions of operation, being typically in the range of $0.5-3$ $\mu \mathrm{m}$ diameter. They can be formed only if sufficient liquid metal can be supplied against the hydrodynamic flow impedance of the source. Since they are electrically charged, the FED droplets can be focussed and steered by electrostatic means. Upon impact on a cool target, the spray freezes to form a highly adherent coatings. As in ion plating $(1,11)$, The presence of the ions is essential for cleaning of the surface of the substrate and to provide an adhesion-promoting interface between substrate and coating by the processes of sputtering and ion mixing (12). For this reason, coatings produced using FED sprayers (13) have been given the name IONCOTE ${ }^{\circledR}$ (Dubilier Scientific Ltd.) Most of the development work to date in FED technology has been concentrated on the production of coatings of gold and gold alloys for electrical applications.

Some of the more important applications of both field emission systems will now be discussed in greater detail.

\section{LMIS Applications - the Role of Gold}

The LMIS is demonstrating considerable potential in two main areas requiring focussing of the ion beam to very small spots (down to $\sim 0.1 \mu \mathrm{m}$ ). The first of these is the rapidly developing technique of Secondary Ion Mass Spectrometry (SIMS) by which surfaces may be analyzed with high spatial

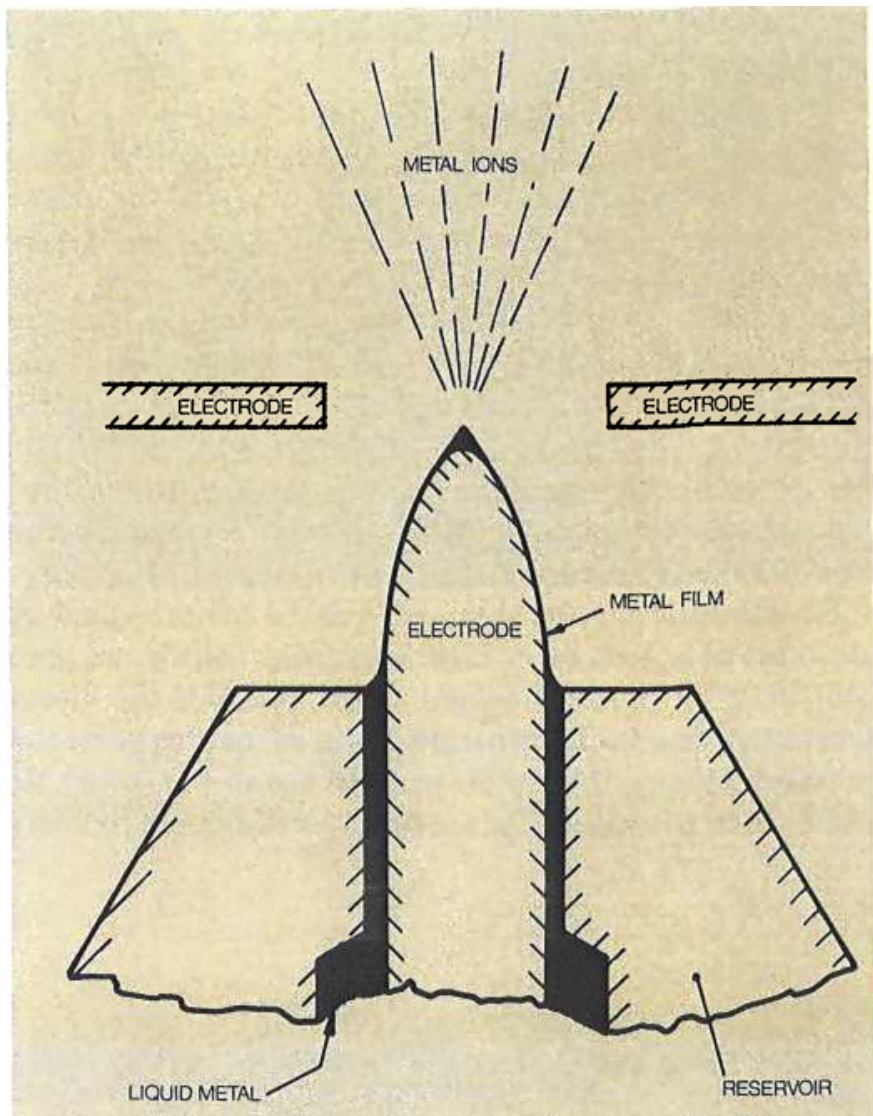

Fig. 1 Schematic diagram showing reservoir and wetted needle emitter used in liquid metal field emission systems

resolution(14). Todate, gold LMIS's have not been used for this application for which sources of gallium and caesium ions will probably be preferred.

It is for the second application of finely focussed ion beams that gold or, to be more precise, alloys of gold are being studied, namely the preparation of silicon microcircuits using highly focussed ion beams.

The semiconductor manufacturing industry is seeking means of producing microcircuits to increasingly finer dimensional tolerances and circuit features of $<1 \mu \mathrm{m}$ with packing densities of a similar order are now required. Such VLSI circuits demand the use of sophisticated new processes to produce these extremely small, dense and highly complex circuit patterns. One such process is the implantation into silicon through an ion-absorbing mask of ions of boron, arsenic and phosphorus. These 'dopant elements' are used to modify the electronic properties of the silicon in the various regions of the microcircuit (2). The ion absorbing masks are produced by a variety of lithographic techniques (for example optical, electron beam, $\mathrm{X}$-ray), but the use of finely focussed ion beams from LMIS's, 
accelerated to energies in excess of $50 \mathrm{KeV}$ is becoming increasingly important $(15,16)$.

Notwithstanding the importance of ion beam lithography, perhaps the most exciting single concept in this fast-developing field is that of direct implantation without a mask by using a finely focussed beam of dopant ions for 'direct writing' of implanted regions. Should this be feasible, the VLSI manufacturing route will be greatly simplified, even revolutionized. In order to be practicable, the submicron doping beam must be of an intensity that only the LMIS is currently able to provide. Unfortunately, the chief silicon dopants (boron, phosphorus and arsenic) are highly volatile and cannot be used to form an LMIS in their pure states. Gold is being used experimentally to solve this problem.

Since the principal dopants used in silicon device technology are unsuitable for use in high brightness LMIS's, an alloy containing the dopant is sought. Then, provided the vapour pressure of the alloy is sufficiently low at its melting point and provided a compatible needle material can also be found, an LMIS can be fabricated. The ion beam produced will contain a fraction of dopant ions depending upon the proportions of the alloy. The lower the melting point of the alloy, the lower will be its vapour pressure during source operation. The focussed ion beam must then be mass-analyzed to separate out the desired dopant ion if direct implantation doping is to be performed. The binary alloys of gold are well documented and have relatively low melting points (17). Moreover, pure gold ion sources have been extensively studied and the good wetting of gold to tungsten needles is well known. In addition, the large differences in atomic mass between gold-197 and the dopants boron-11, phosphorus-31, arsenic-75 and antimony-122 encourages optimism that efficient mass filtering can be achieved. Unfortunately, while gold forms several useful low melting binary eutectic alloys with elements such as $\operatorname{tin}\left(280^{\circ} \mathrm{C}\right)$ and silicon $\left(370^{\circ} \mathrm{C}\right)$, the quest for dopant-bearing alloys has necessitated the use of more complex ternary systems. The way has been led by Japanese and American workers who have studied several gold, platinum and other systems with the results shown in Table $\mathrm{I}(21,22,23)$.

More recently, the value of silicon as a resist-exposing ion has led to the development of an alloy source for experiments on ion beam lithography. The reason for this is simple - any silicon ions which pass completely through the resist and enter the silicon substrate will have no deleterious effect upon its electrical properties. The goldsilicon LMIS source is already producing promising results in experiments on ion beam lithography (24).

\section{The FED Sprayer in High Technology}

There have been some experimental investigations of FED sprayers of aluminium (25) and its alloys (26) but most progress has been made using sprayers of gold and gold alloys and a reliable FED module has now been developed (27). As stated earlier, ION$\mathrm{COTE}^{\circledR}$ metal films are formed by agglomeration of the tiny liquid droplets from the FED sprayer as they strike the target surface.

The mean diameter of these droplets varies with the value of the applied electric field, which also determines the current of ions emitted by the sprayer. At currents up to $\sim 150 \mu \mathrm{A}$ the FED spray is composed almost entirely of ions, though there is evidence to suggest the emission of extremely small clusters and 


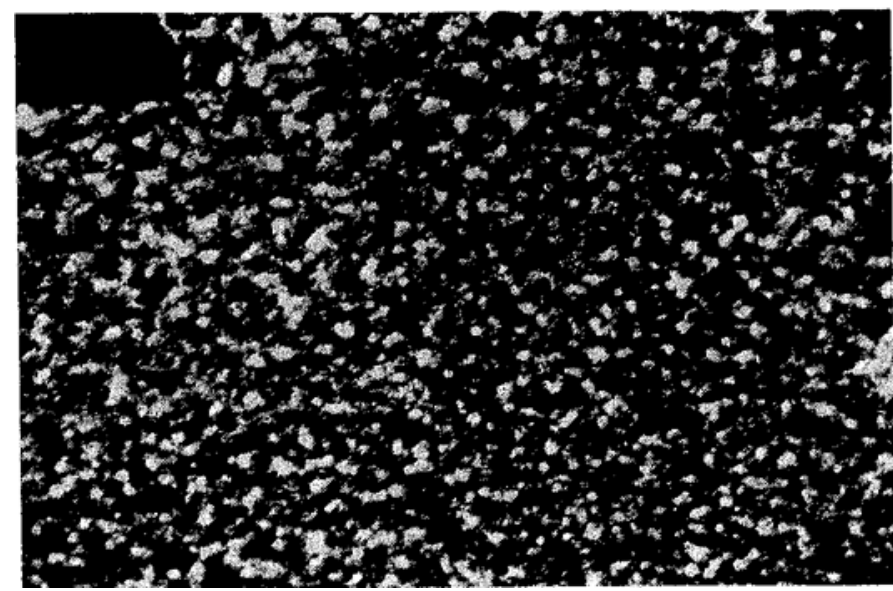

(a) $I=100 \mu \mathrm{A}$

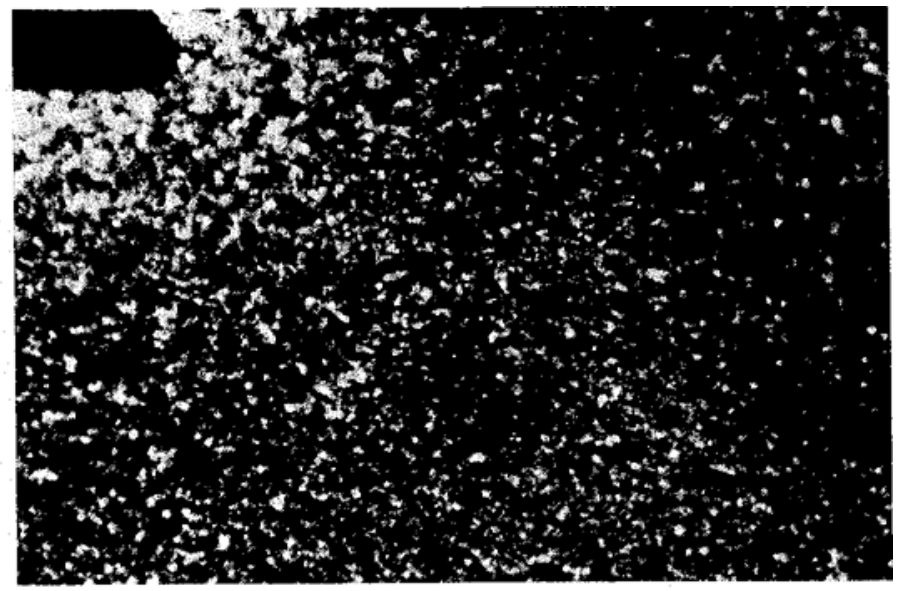

(b) $150 \mu \mathrm{A}$

Fig. 2 Scanning electron micrographs of FED coatings showing variation of droplet size with emision current (I)

(c) $300 \mu \mathrm{A}$

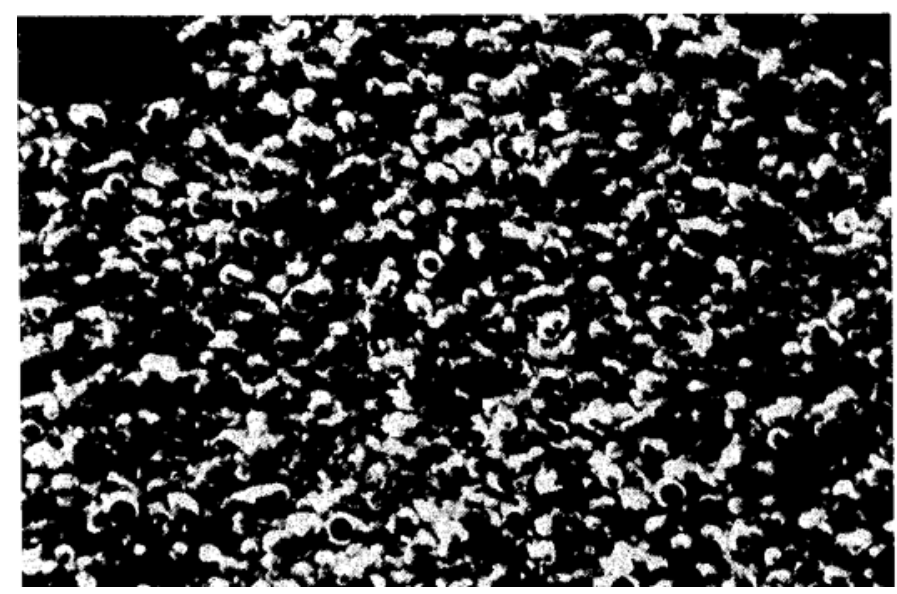

droplets with diameters ranging from $10 \mathrm{~nm}$ to $100 \mathrm{~nm}(28)$. In this so-called ion mode, high energy metal ions are used to sputter-clean the surface prior to deposition at higher currents (that is at higher voltages and electric fields) when increased field disruption of the liquid surface occurs and the ratio of droplets to ions in the spray is increased. In this sprayer or coating mode, IONCOTE ${ }^{\boxplus}$ deposits are produced. The coating mode begins at a current of about $200 \mu \mathrm{A}$ (Figure 2(a)) when the average droplet diameter $d$ is less than $1 \mu \mathrm{m}$ and the deposition rate $R$ is correspondingly small $\left(R<0.2 \mu \mathrm{mcm}^{2} / \mathrm{min}\right)$. At much (d) $500 \mu \mathrm{A}$

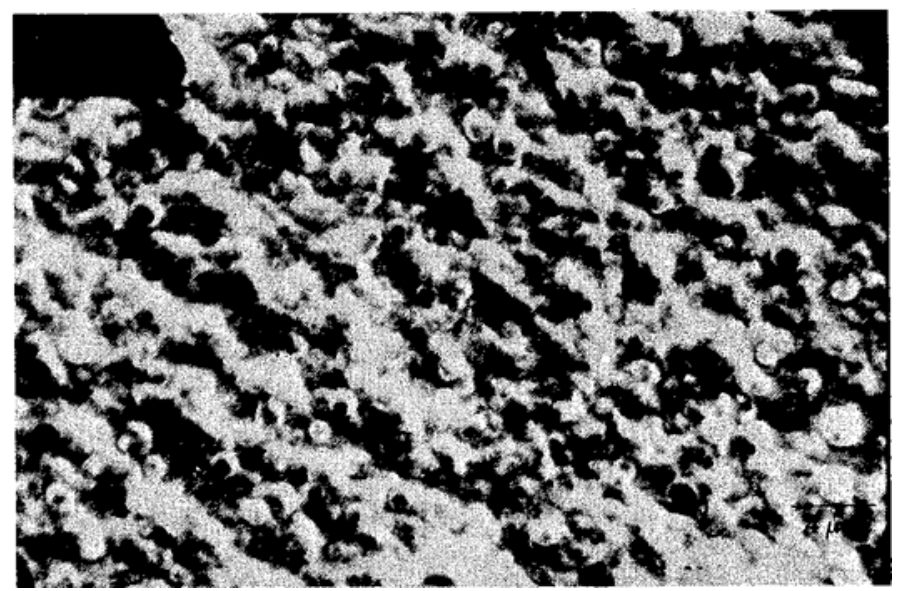

higher currents (greater than $700 \mu \mathrm{A}$, see Figure 2(c)), deposition rates are significantly increased $(R \sim 1 \mu \mathrm{m} \mathrm{cm} / \mathrm{min})$ but this is achieved at the expense of deposit quality which is far coarser $(d \sim 4 \mu \mathrm{m})$. The optimum coating mode for most applications occurs at currents of about $600 \mu \mathrm{A}(R \sim 0.5 \mu \mathrm{m}$ $\mathrm{cm}^{2} / \mathrm{min}, d \sim 2 \mu \mathrm{m}$ ), as shown in Figure 2(b). These coatings are highly adherent. In fact, attempts to measure adhesion of FED coatings of gold on a variety of substrates including glass have revealed values of adhesion in excess of $2 \times 10^{7} \mathrm{~N} / \mathrm{m}^{2}$. Failure is normally due to breaking of the substrate or of the test 

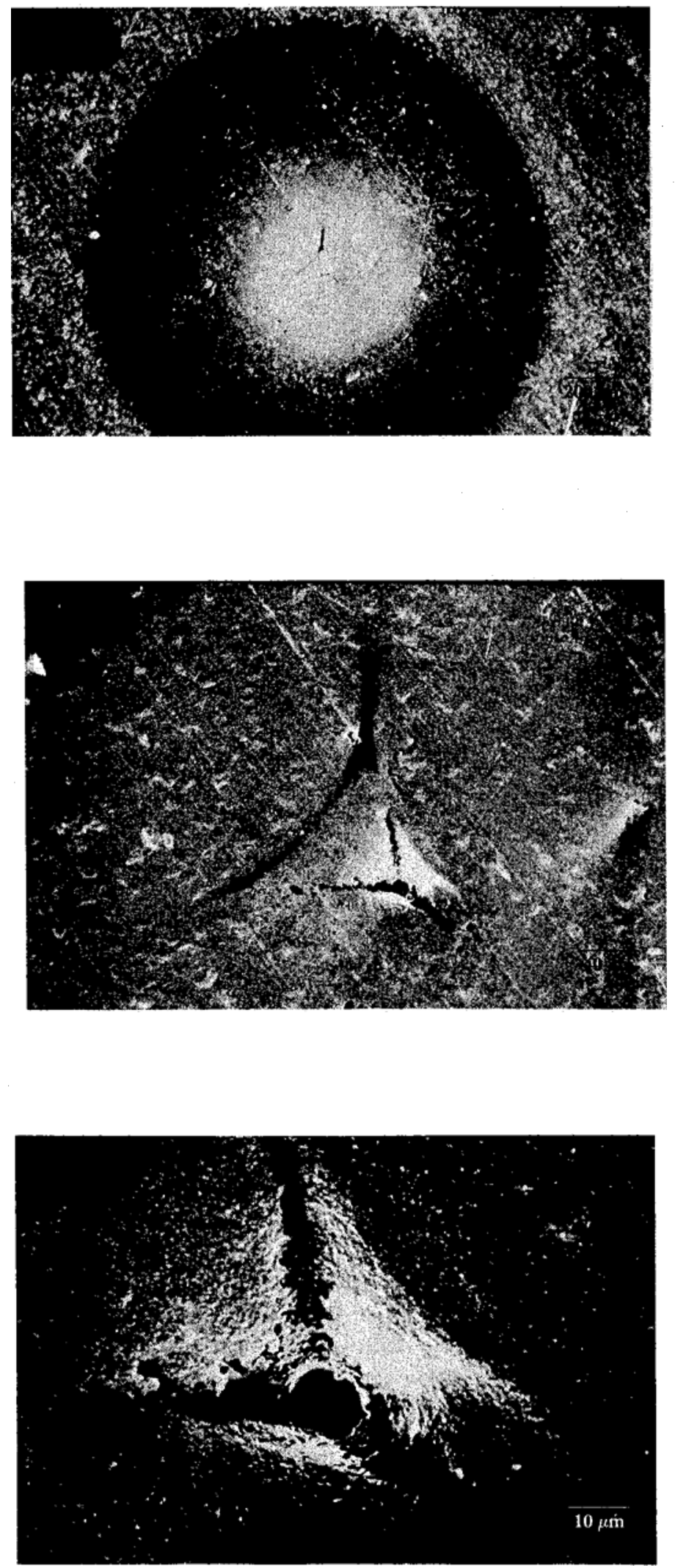

stub-to-gold bond with no damage to the gold-to-substrate bond. The potential of such coatings is indicated by the fact that recent thermal compression bonds using silver FED coatings have achieved strengths of up to $10^{8} \mathrm{~N} / \mathrm{m}^{2}$. This promises to develop into an important new process for bonding of components. Thermal compression bonding of quartz to stainless steel for manufacture of high temperature vacuum-tight windows is just one possibility (29).

As in the case of the LMIS, however, the greatest potential of the FED process is in applications which exploit fine focussing and electrical deflection of the droplet beam. Electrical focussing and deflection of FED sprays has been a major recent development (30). The focussing and deflection of electrons and ions using electrostatic lenses is, of course, commonplace, but the successful use of such lens systems to focus a spray of droplets of comparatively massive charge might at first sight seem surprising. The key to this success lies in the fact that, in contrast to magnetic lenses, the deflection and focussing of charged particles using radial electric fields is independent of particle charge and mass. This is best illustrated by considering the simple case of the deflection in an electric field $E$ of an energetic particle carrying charge $Q$. This is governed by the expression:

$$
\frac{d y}{d z}=\frac{Q E Z}{T}
$$

where $T$ is the kinetic energy of the particle which travels prior to deflection in the axial (z) direction. This kinetic energy was gained during initial acceleration through some axial potential difference $V_{0}$ and may be expressed as:

$$
T=Q_{0} V_{o}
$$

where $Q_{o}$ is the charge on the particle during acceleration. Provided the particle is not subjected to any accelerating or decelerating (axial) fields following its initial accelêration, the quantity $T$ will be invariant during its flight through the system. If there is no change in the electric charge of a droplet, then its transverse deflection is given by:

$$
\frac{d y}{d z}=\frac{1 E Z}{4 V_{o}}
$$

Even if the particle charge does change before deflection, the charge-to-mass ratio is still immaterial and deflection depends only upon the 'beam potential' $V_{B}$ at the time of exposure to the transverse field, that is:

Fig. 3 Scanning electron micrographs of a well-focussed spot deposit showing central 'pip' ( $I=200 \mu \mathrm{A})$ 


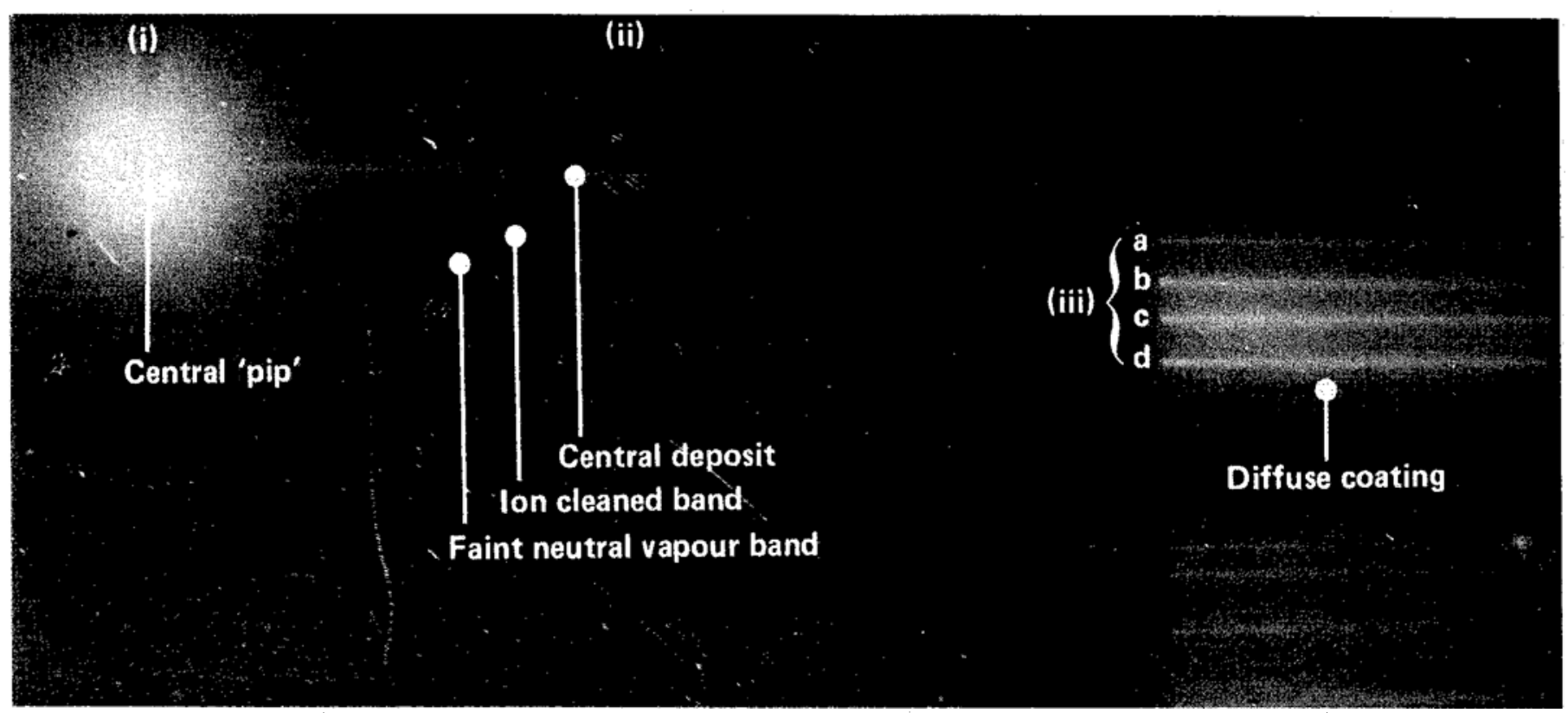

Fig. 4 Photograph of line deposits generated by mechanical translation of a target substrate under an FED beam:

(i) The diffuse spot produced under an FED beam

(ii) A line deposit several hundreds of micrometres wide is produced by single pass translation of the substrate under the beam. The deposit is bounded by an ion cleaned region and a very faint band due to deposition of evaporated neutral atoms

(iii) Multiple pass scanning broadens the deposit. Lines a, b, $c$ and $d$ are produced by 2, 3, 4 and 5 passes respectively

$$
\frac{d y}{d z}=\frac{1 E Z}{4 V_{B}}
$$

The same argument applies to focussing as well as to deflection.

A series of experiments to investigate the electrical properties of the FED gold droplet spray and to evaluate its technological potential has been conducted and full details are be reported elsewhere (31). Some of the results of this recent work may be summarized as follows.

The FED sprayer delivers droplets and ions which can be focussed and deflected using simple electrostatic einzel lenses. There is in addition a small neutral vapour component which, of course, cannot be focussed. A scanning electron micrograph showing a typical spot deposit generated by an FED sprayer is shown in Figure 3 . The gold vapour deposit is too nebulous to be seen but the effects of the ion and droplet components are visible. The dark outer ring is a region of substrate which has been cleaned by the ion component in the focussed spray. Inside this is the droplet-coated spot extending to a radius of $\sim 200$ $\mu \mathrm{m}$. At its centre is a 'pip' of some $30 \mu \mathrm{m}$ radius where the peak of the droplet beam has built up a coating of some tens of micrometres in a few minutes.

Electrical deflection has been used to generate coated lines from such focussed spots and rectangular deposits have been formed using raster scan generators. Whether they are produced by electrical deflection of the focussed beams or by mechanical translation of the target under a fixed beam, the width of the coated lines depends upon the 'exposute' of the substrate, In other words, the coated width will effectively increase with increasing droplet dose due to the enhanced effects of the outer, less intense regions of the droplet distribution. With mechanical scanning, the coated width increases with the number of passes of the substrate under the beam as shown in Figure 4 . The effect of the ion component of the beam is visible in Figure 4 as a band of sputter-cleaned substrate on either side of the coated gold line.

Even with the simple einzel lens arrangements used in experiments to date, the considerable technological promise of the FED technique is apparent. Already gold lines a few hundreds of micrometres wide have been produced and, with the aid of improved optics, spots and lines $60 \mu \mathrm{m}$ or less across should soon be feasible as indicated in Figure 3 . Thus the process might well be adapted for the generation of complex patterns of contacts and interconnections such as those used in hybrid microcircuit technology. FED coatings for this application could be written by electrical pattern generators under microcomputer control in a single-step vacuum deposition process to replace the multi-step lithographic and masking techniques used at present.

Finally, it is worth listing some of the advantages of the IONCOTE $^{\circledR} /$ FED process as was done for ion plating at the start of this article. The process provides: 
(1) No harmful effluent

(2) Vacuum cleanliness

(3) Good film quality

(4) Excellent adhesion

(5) Electrical focussing and deflection for maskless pattern generation.

FED has, in fact, all the advantages of ion plating except throwing power - it is a highly directional process and as such its ability to coat 'around corners' is negligible in contrast to that of ion plating. The adhesion obtained in FED is probably greater than that obtained by any other coating technique, but its most outstanding advantages are associated with the unique facility for electrically-controlled generation of pattern coatings which it affords. FED has some similarities to the Ionized Cluster Beam Deposition technique (ICBD) pioneered at Kyoto University, Japan (32), in which atomic clusters or microdroplets as small as $5 \mathrm{~nm}$ are employed.

\section{Conclusions}

The two liquid metal field emission systems, namely the LMIS and FED sprayer, are clearly of potential technological importance. The full impact of the LMIS on the fast-developing technology of submicron microcircuit fabrication will surely be seen during the next five years. Ion beam lithography will undoubtedly develop first, but direct implantation writing of microcircuits, using dopant ions generated by alloy LMIS's offers a significant prize to the ion source technologist

Field emission deposition (FED) sprayers for the production of IONCOTE $^{\circledR}$ coatings have a less certain future at this stage in their development, but significant progress has recently been made. The maskless generation of hybrid microcircuit conductor pathways, using FED sprayers linked to computerdriven pattern generators, may be only a few years away.

In the development of both these field emission systems, liquid gold is playing an important experimental role.

\section{Acknowledgements}

The author's personal thanks go to Messrs. C. Mahony, L. G. Gowland and D. Jefferies for their contributions to this work.

\section{References}

1 E W. Williams, Gold Bull., 1978, 11, (2), 30-34

2 P.H. Rose, Gold Bull., 1980, 13, (1), 2-6

3 R. Clampitt and D.K. Jefferies, Nucl. Instrum. Methods, 1978, 149, 734.742

4 G.L.R. Mair, '24th Int. Field Emission Symp.', Oxford, 1977, unpublished data

5 P.D. Prewett and D.K. Jefferies, J. Phys. D., 1980, 13, 1747

6 P.D. Prewett, D.K. Jefferies and T.D. Cockhill, Rev. Sci. Instrum., 1981, 52, $562-566$

7 G.I. Taylor, Proc. R. Soc. (London), 1964, A280, 383

8 P.D. Prewett, G.L.R. Mair and S.P. Thompson, J. Pbys. D., 1982, 15, 1339

9 J.R. Oppenheimer, Phys. Rev., 1928, 13, 66

10 E.W. Muller and T.T. Tsong, 'Field Ion Microscopy - Principles and Applications', 1969, Elsevier, Amsterdam

11 D.M. Mattox, J. Vac. Sci. Technol., 1973, 10, 47

12 G. Carter and D.G.Armour, Thin Solid Films, 1981, 80, 13

13 P.D. Prewett, L. Gowland, K.L. Aitken and C.M.O. Mahony, Thin Solid Films, 1981, 80, 117-124

14 P.D. Prewett and D.K. Jefferies, in 'Proc. Conf. Low Energy Ion Beam-2, $1980^{\prime}$, Inst. Phys. Series 54, p. 316

15 R.L. Seliger, R.L. Kubena, R.D. Olney, J.W. Ward and V. Wang, J. Vac. Sci. Technol., 1979, 16, 1610

16 J.R.A. Cleaver and H. Ahmed, J. Vac. Sci. Technol., 1981, 19, 1145

17 M. Hansen, 'Constitution of Binaty Alloys', McGraw-Hill, 1958

18 A. Wagner and T.M. Hall, J. Vac. Sci. Techinol., 1979, 16, 1971
19 P. Sudraud, J. van de Walle, C. Colliex and P. Trebia, J. Physique, 1979, 40 L207

20 A.R. Waugh, J. Pbys. D: Appl. Pbys., 1980, 13, L203

21 R.L. Seliger and V. Wang, '28th Int. Field Emission Symp.', Portland, OR., 1981 , unpublished

22 K. Gamo, Y. Inomoto, Y. Ochiai and S. Namba, J. Vac. Sci. Tecbnol., $1981,19,1182$

23 Y. Ochiai, Y. Inomoto, T. Ukegawa, K. Gamo and S. Namba in 'Proc. 5th Int. Symp. on Ion Sources and Ion Assisted Technology, ISIAT' 81', edited by T. Takagi, Kyoto, Japan, 1981, pp. 175-182

24 Dubilier Scientific, Ltd., A bingdon, U.K. - unpublished data

25 J. Mahoney, A.T. Forrester, J. Perel and B. Kalensher, 'Ion Assisted Sources Conf. Record', I.E.E.E., Sept., 1980

26 R. Clampitt, M.G. Scott, K.L. Aitken, L. Gowland and P.D. Prewett, in 'Proc. 3rd Int. Conf. on the Rapid Quenching of Metals', Brighton, Vol. 1, Met. Soc, London, 1978

27 P.D. Prewett, L. Gowland; K.L. Aitken and C.M.O. Mahony,Thin Solid Films, 1981, 80, 117

28 R.F.C. Farrow, A.G. Cullis, A.J. Grant, G.R. Jones and R. Clampitt, Thin Solid Films, 1979, 58, 189

29 C.M.O. Mahony, UKAEA, Culham Laboratory, unpublished data

30 C.M.O. Mahony, L. Gowland and P.D. Prewett, in 'Proc. 29th Int. Field Emission Symp.', edited by H.O. Andrén and H. Nordén, Goteborg, Sweden, 1982, pp. 383-391

31 C.M.O. Mahony, L. Gowland and P.D. Prewett, in 'Proc. Conf. Low Energy Ion Beam-3', Loughborough, Inst. Phys., March, 1983 